\title{
HYDRONEPHROSIS IN INFANCY
}

\author{
BY \\ A. R. BEARN \\ From The Hospital for Sick Children, Great Ormond Street, and the Middlesex Hospital, London
}

(RECEIVED FOR PUBLICATION NOVEMBER 9, 1955)

Hydronephrosis of the pelvi-ureteric type rarely presents in infancy. Nixon (1953) found only one case in a child under the age of 6 months out of 78 cases seen at The Hospital for Sick Children, Great Ormond Street, between 1929 and 1950. It is, however, a condition which can be treated by conservative surgery and it is important that it should not be overlooked. The following two cases of pelvi-ureteric hydronephrosis are described because they closely resembled other causes of renal enlargement.

\section{Case Reports}

Case 1. G.S., a boy, was admitted to The Hospital for Sick Children under Professor Moncrieff on March 18, 1955 , at the age of 2 months. His abdomen had been enlarged since birth. For four days before admission he had been vomiting intermittently. He had been having his bowels open three times a day.

On examination he was seen to be a well-fed infant.

The abdomen was large and there was divarication of the recti. The liver and spleen were not palpable. There was an easily palpable mass with a smooth rounded lower pole in each loin, the right being larger than the left. The bladder was not palpable. On rectal examination nothing abnormal was found.

The blood urea level was $38 \mathrm{mg}$. per $100 \mathrm{ml}$.

A radiograph of the abdomen showed that there was a large soft tissue mass lying posteriorly on each side of the abdomen. There was no calcification in the masses and no abnormality in the spine (Fig. 1).

The provisional diagnosis was of polycystic kidneys.

On the third day after admission the infant's bowels were open five times. The stools were offensive and he lost weight. He was therefore transferred to the gastroenteritis unit. No pathogens were found in the stools. He was given a week's course of chloramphenicol, but the relaxed stools continued for three weeks and even then did not completely return to normal.

It was noted during this time that the size and tenseness of the loin swellings varied a little from day to day. The possibility of bilateral hydronephrosis was therefore considered and an intravenous pyelogram was performed which showed concentration of dye in each kidney, but detail was grossly distorted.

The blood urea level was now $46 \mathrm{mg}$. As the diagnosis

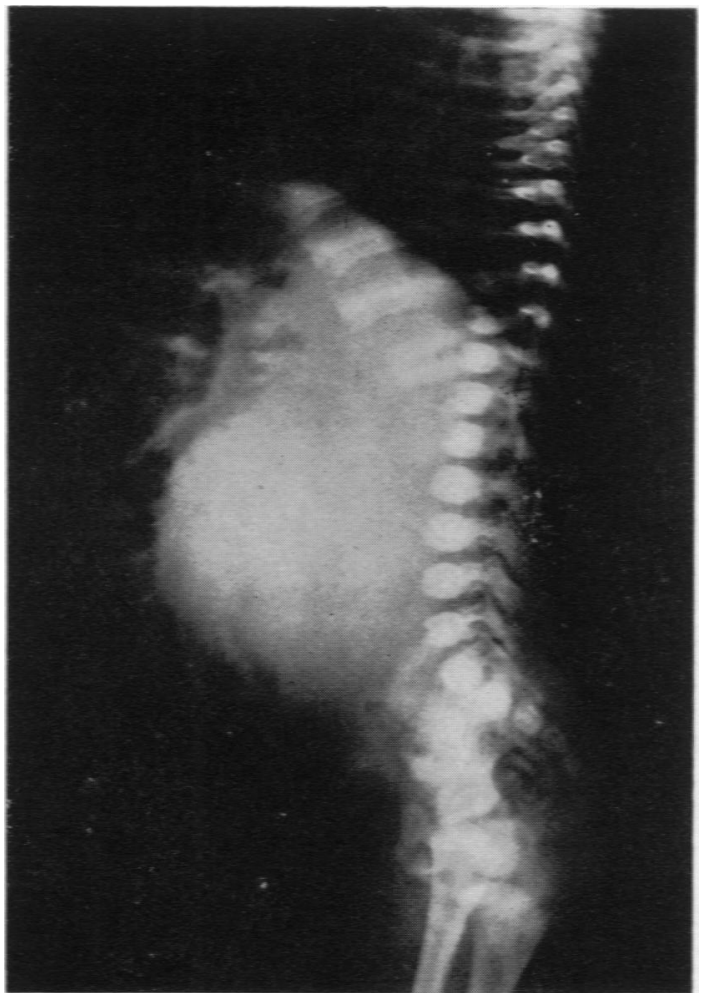

Fig. 1.-Lateral radiograph of the abdomen of Case 1, showing a huge ofacity in the loin.

was still in doubt, a retrograde pyelogram was ferformed. On April 13 Mr. D. I. Williams ferformed cystoscopy and a retrograde pyelogram. The bladder, bladder neck and ureteric orifices were all normal. The retrograde pyelogram showed gross bilateral hydronephrosis (Fig. 2:

It was decided that both kidneys should be explored with a view to performing plastic operations, and the right kidney was explored on April 15 by Mr. D. I. Williams.

Through a right loin incision a giant hydronephrosis of the renal pelvis was found. The ureter was of normal size. A Hynes-Anderson (Anderson, 1951) type of 


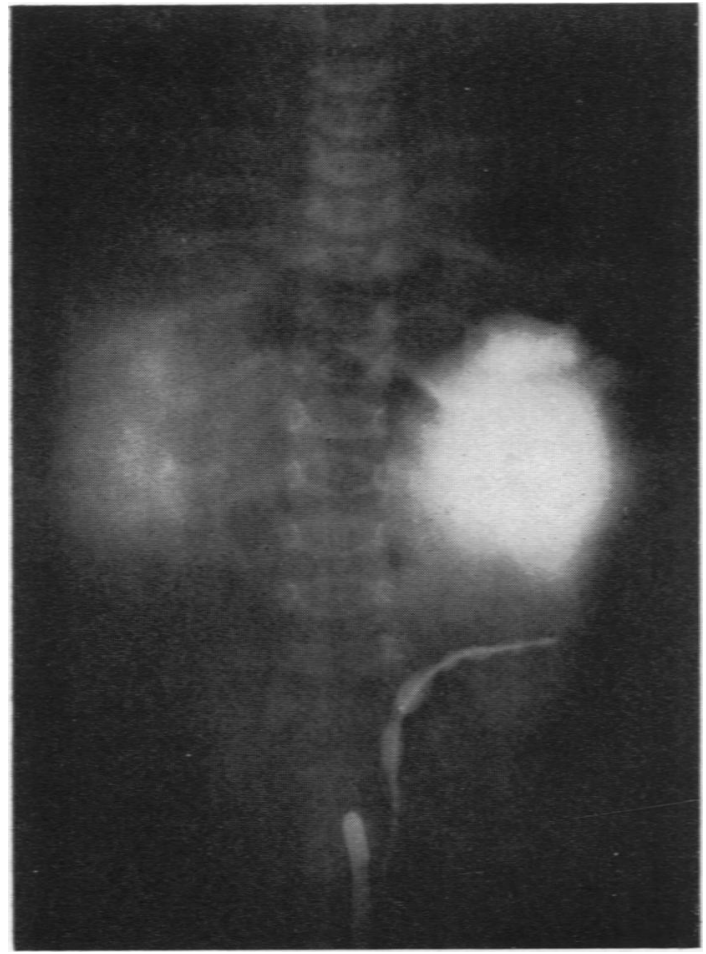

FIG. 2.-Retrograde pyelogram of Case 1, showing bilateral hydronephrosis.

plastic operation was carried out on the pelvi-ureteric junction. A nephrostomy was performed by inserting a Malecot catheter through the renal substance. The wound was closed with drainage.

The nephrostomy tube was removed on the tenth day. Post-operative convalescence from this operation was uneventful.

On May $4 \mathrm{Mr}$. D. I. Williams found a similar state of affairs as on the opposite side through a left loin incision. A left Hynes-Anderson pyeloplasty was performed and a nephrostomy tube left in to drain the kidney.

The post-operative course was a little more stormy than after the first operation.

The stools returned to normal after the second operation and it was thought possible that the multiple loose stools had been due to a partial obstruction caused by the giant renal swellings.

An intramuscular pyelogram was carried out on June 9, and showed reasonable excretion on both sides.

The patient was finally discharged on June 13, 1955, clinically very much improved.

Case 2. C.E., a girl, was admitted to the Middlesex Hospital under Dr. E. W. Hart on September 22, 1952, at the age of 5 weeks. The abdomen had been distended since birth and an abdominal tumour had been found at the Infant Welfare Clinic. She was taking feeds readily and gaining weight.

On examination she was a small, rather wasted baby. The heart and lungs were apparently normal. The abdomen was enormously distended. There was a small umbilical hernia and there were dilated veins over the abdomen. There was a huge, firm swelling, of smooth outline, filling the right side of the abdomen, which was dull to percussion. On rectal examination, nothing abnormal was found.

Chest radiographs showed that the heart and lungs were normal. There was an abnormality of the posterior part of the right ninth rib, the appearances being in favour of a deposit (Fig. 3).

A radiograph of the abdomen showed a large mass in the right side of the abdomen, arising posteriorly (Fig. 3).

A skeletal survey brought no evidence of any other abnormality.

The provisional diagnosis was of Wilms tumour.

On September 27 Mr. C. J. B. Murray opened the abdomen by a right paramedian incision. A very large retroperitoneal tumour was found in the right loin. When dissected out it proved to be an enormous hydronephrosis of the renal pelvis. The renal tissue consisted of a thin rim stretched out over the surface. The ureter was of normal size. The left kidney was palpated and felt normal. A right nephrectomy was therefore carried out (Fig. 3).

The post-operative course was uneventful. Further radiographs of the ninth rib showed the lesion to be a fracture which had united by the time the baby was discharged on October 21.

Following this operation, she remained well until May 29, 1953, when she was readmitted because she had been off colour for two days. She was found to have an Esch. coli pyelitis. The blood urea was $33 \mathrm{mg}$.

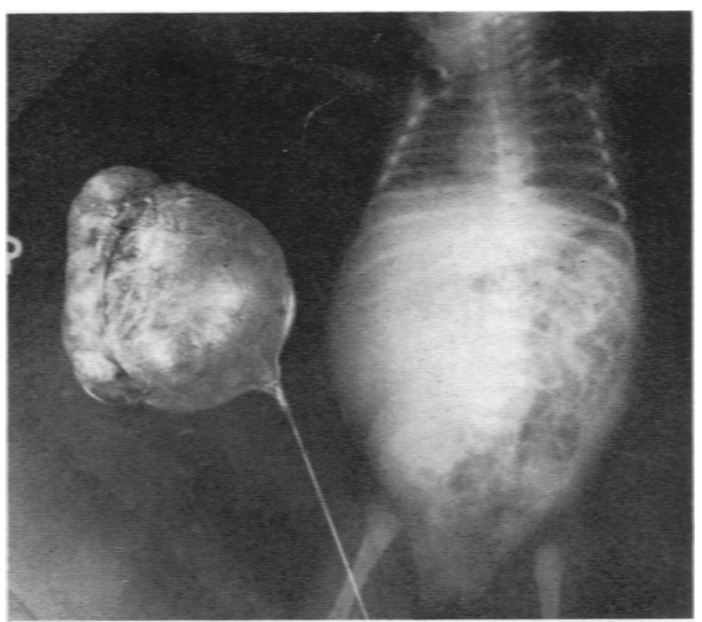

Fig. 3.-Radiograph of the abdomen of Case 2, showing an opacity in the right loin. There is a lesion in the right ninth rib. The hydronephrotic right kidney, removed at operation, is superimposed on the radiograph. 
$100 \mathrm{ml}$. The infection responded to sulphafurazole. An intramuscular pyelogram was performed and showed hydronephrosis of the remaining left kidney.

She was discharged on July 17, 1953.

She was again admitted to the Middlesex Hospital on August 14, 1953, with a temperature of $103^{\circ} \mathrm{F}$. and was again found to have an Esch. coli pyelitis. The infection responded to sulphafurazole. The blood urea was $37 \mathrm{mg}$. $100 \mathrm{ml}$.

In view of the two attacks of pyelitis and the finding of left hydronephrosis, it was decided to explore the left kidney.

On September 2 Mr. C. J. B. Murray exposed the left kidney through a loin incision. A hydronephrosis of the renal pelvis was found. The ureter was of normal size. A plastic operation was performed on the pelviureteric junction. A nephrostomy tube was used to drain the renal pelvis.

Recovery from this operation was uneventful. The nephrostomy tube was removed on the seventh day. The child was finally discharged on September 19, 1953, in excellent condition.

She was last seen as an out-patient on December 20, 1954 , and was very well.

An intravenous pyelogram performed at this time showed good secretion, though still some hydronephrosis of the left kidney.

The blood urea was $23 \mathrm{mg}$. per $100 \mathrm{ml}$.

\section{Discussion}

The first case illustrates the importance of differentiating hydronephrosis of the pelvi-ureteric type from polycystic kidneys and from hydronephrosis due to lower urinary tract obstruction. Infantile polycystic disease is very rare in infants who survive more than a few days after birth, and in those who do survive there are almost certain to be signs of severe renal failure. The commonest cause of bilateral cystic enlargement of the kidneys in infancy is lower urinary tract obstruction (Williams, 1955).
Most of these infants have congenital valves in the posterior urethra though some have bladder neck obstruction and others congenital strictures of the urethra. The majority present with signs of renal failure and the bladder is usually palpable though sometimes it is quite small. This means that bilateral cystic enlargement of the kidneys in infants, in the absence of renal failure, is most likely to be due to pelvi-ureteric hydronephrosis.

The second case illustrates the difficulty of distinguishing a tense hydronephrosis from a Wilms tumour. Wilms tumour is rare in infancy; during the 25 years from 1925 to 1951 , out of 75 cases of Wilms tumour seen at The Hospital for Sick Children, only one was in a child under the age of 6 months.

These cases illustrate the importance of fully investigating all cases of renal enlargement in infancy. If renal failure is absent, an intravenous pyelogram should be performed. If the diagnosis is still uncertain, cystoscopy, urethroscopy and retrograde pyelography should be carried out.

\section{Summary}

Two cases of hydronephrosis in infants which were successfully treated by conservative operations are described. The differential diagnosis of renal enlargement in infancy, and the importance of their full investigation is discussed.

My thanks are due to Professor Moncrieff and Mr. D. I. Williams for permission to report Case 1, and to Dr. E. W. Hart and Mr. C. J. B. Murray for Case 2. and especially to Mr. D. I. Williams for his help and encouragement in preparing this paper.

\section{REFERENCES}

Anderson, J. C. (1951). Proc roy. Soc. Med., 44. 4.

Nixon, H. H. (1953). Brit. J. Surg., 40, 601.'

Williams, D. I. (1955). Personal communication. 